\title{
To Buy or Not to Buy? \\ Uncertainty, Irreversibility, and Heterogeneous Investment Dynamics in Italian Company Data
}

Stephen R. Bond

and Domenico Lombardi 


\title{
IMF Working Paper
}

Office of the Executive Director for Italy

\section{To Buy or Not to Buy? Uncertainty, Irreversibility, and Heterogeneous Investment Dynamics in Italian Company Data}

\author{
Prepared by Stephen R. Bond and Domenico Lombardi ${ }^{1}$ \\ Authorized for distribution by Pier Carlo Padoan
}

June 2004

\begin{abstract}
This Working Paper should not be reported as representing the views of the IMF. The views expressed in this Working Paper are those of the author(s) and do not necessarily represent those of the IMF or IMF policy. Working Papers describe research in progress by the author(s) and are published to elicit comments and to further debate.

This study tests for the presence of real options effects induced by uncertainty and (partial) irreversibility on fixed capital investment using Italian company data. The approach recognizes that firm-level investment spending may, itself, be aggregated over multiple investment decisions in separate types of capital goods and emphasizes effects of uncertainty on short-run investment dynamics. Using a survey-based measure of uncertainty related to the assessment of managers responsible for the firms' investment plans, the study finds evidence of heterogeneous and nonlinear dynamics pointing to a slower adjustment of investment in response to demand shocks at higher levels of uncertainty. The results also point to an additional source of nonlinearity originating from a convex response of investment to demand shocks.

JEL Classification Numbers: C23, D8, D92, E22

Keywords: Investment, Real Options, Panel Data

Author’s E-Mail Address: steve.bond@nuf.ox.ac.uk, dlombardi@imf.org

\footnotetext{
${ }^{1}$ S. Bond is Visiting Professor at Oxford University; Research Fellow at Nuffield College, Oxford; and Programme Director at The Institute for Fiscal Studies (IFS). D. Lombardi is Advisor to the Executive Director for Italy. This project was started when he was in the Bank of Italy's Research Department. The authors thank N. Bloom, R. Flood, T. Krueger, G. Parigi, and participants in the North American Econometric Society Meeting, University of Maryland for helpful comments. C. Di Benedetto and S. Siciarz provided excellent assistance with data and editing, respectively. The authors gratefully acknowledge financial support from the Economic and Social Research Council (ESRC), Oxford University, and the ESRC Centre for Fiscal Policy at IFS.
} 
Contents Page

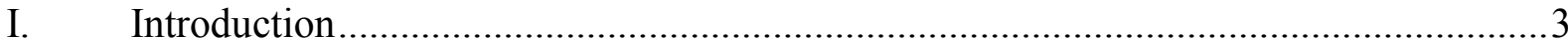

II. A Review of the Literature .........................................................................

A. Investment Dynamics Under Irreversibility and Uncertainty ...............................5

III. Econometric Specifications of Investment Behavior...........................................

A. A Baseline Dynamic Model ............................................................................ 7

B. An Augmented Error-Correction Model ............................................................... 8

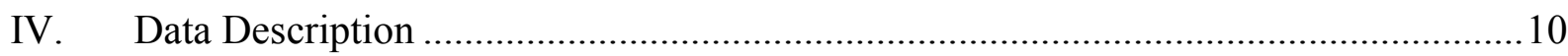

A. Stylized Facts ...................................................................................... 10

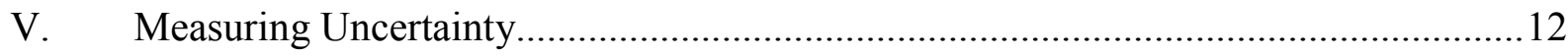

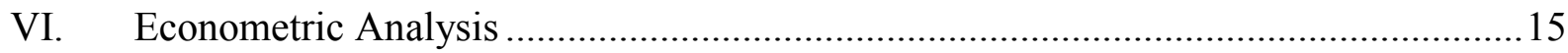

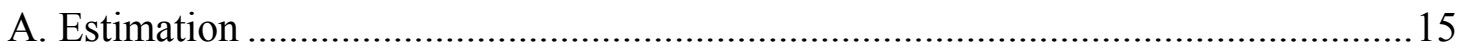

B. Empirical Results and Their Policy Implications............................................ 16

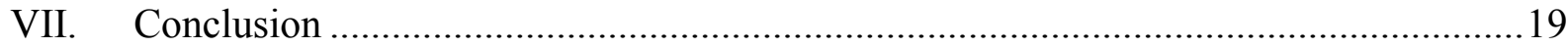

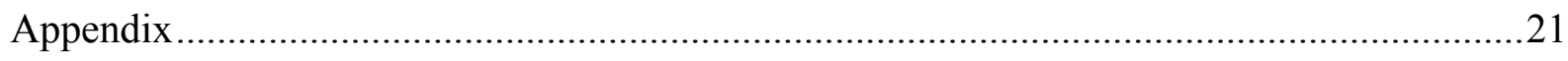

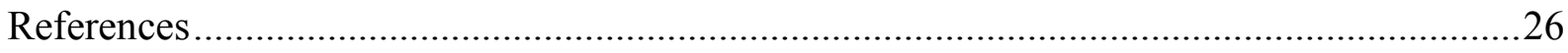

Tables

1. Frequency of Zero Investment and Disinvestment Episodes.................................... 11

2. Frequency of Zero Investment and Disinvestment Episodes.................................. 12

3. Investment and Expected Investment Rates ................................................ 14

4. Firms with High and Low Uncertainty ................................................................ 15

5. Investment Equations: One-Step Results ........................................................... 18

6. Investment Equations: Two-Step Results ............................................................. 19

Appendix Tables

A1. Comparison of SIM and SIM-CADS Samples ...............................................24

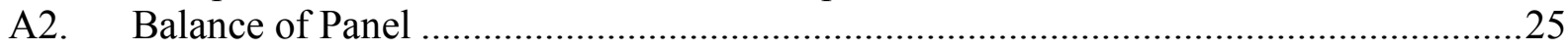

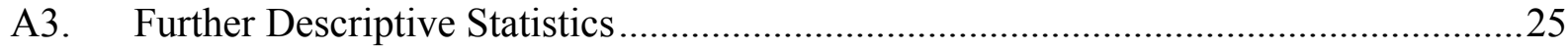




\section{INTRODUCTION}

Aggregate investment spending is an important source of fluctuations over the business cycle. A puzzling aspect of such fluctuations is that they sometimes occur in connection with relatively small shocks or policy impulses. Previous contributions on the "small shocks, large cycles" puzzle have focused on borrowers' credit-market conditions and their ability to propagate an initial real or monetary shock to the rest of the economy (Bernanke, Gertler, and Gilchrist (1996 and 1998) and Hubbard (1998)).

In this paper, we consider an alternative mechanism that may explain the observed large cyclical movements of investment with respect to the business cycle, based on the firms' behavior under uncertainty. Important early contributions on the relationship between investment and uncertainty include those of Lucas and Prescott (1971), Hartman (1972), Nickell (1977a and 1977b), and Abel (1983). In the last decade, research has focused on a class of models in which real options influence investment behavior, since firms may have an incentive to wait for the arrival of new information, thus postponing the implementation of their investment plans (Bertola (1988), Pindyck (1988), Caballero (1991), and Dixit and Pindyck (1994); see also the survey by Carruth, Dickerson, and Henley (2000)).

Theoretical analyses have shown that the impact of uncertainty on the level of the capital stock in the long run is ambiguous in this class of models (Abel and Eberly (1999) and Caballero (1999)). Perhaps for this reason, empirical studies have not reached any consensus on the sign or significance of this long-run relationship. However, more recent theoretical contributions have emphasized the effects of uncertainty on short-run investment dynamics (Abel and Eberly (1999) and Bloom (2000)), and empirical studies have found evidence consistent with the predicted slower response of investment to demand shocks at higher levels of uncertainty (Guiso and Parigi (1999) and Bloom, Bond, and Van Reenen (2003)).

This paper extends this empirical research using data on Italian firms. In particular, we test for the nonlinear and heterogeneous investment dynamics predicted by models with partial irreversibility and uncertainty, using a measure of uncertainty related to the assessment of managers responsible for the firms' investment plans.

We find evidence of heterogeneity across firms in investment dynamics and, in particular, of slower adjustment of investment in response to demand shocks at higher levels of uncertainty. Interestingly, our findings also point to an additional source of nonlinearity originating from a convex response of investment to demand shocks.

The paper is organized as follows. In Section II, we provide a brief review of the most recent literature on irreversible investment under uncertainty; in Section III, we outline our econometric specification, while in Section IV, we describe the features of our dataset; in Section V, we present our measure of uncertainty; Section VI reports the empirical results and comments on their policy implications; and Section VII concludes our study. 


\section{A Review of the Literature}

Early contributions have shown that uncertainty may increase the value of the marginal unit of capital, thus leading to more capital accumulation. Hartman (1972) and Abel (1983) investigate the impact of uncertainty on capital accumulation by focusing on the investment behavior of a competitive firm with constant returns to scale and (symmetric) convex adjustment costs. Under these assumptions the resulting profit function is convex in price and, therefore, a mean-preserving increase in price uncertainty raises the expected return on a marginal unit of capital under the Jensen's inequality, therefore enhancing the attractiveness of additional investment.

Importantly, the (symmetric) convexity of adjustment costs rules out the possibility that investment expenditures may exhibit some degree of irreversibility, a feature first emphasized by Arrow (1968). When investment is completely irreversible and future demand, cost conditions and other relevant market variables are uncertain, firms have an incentive to wait until more information becomes available. On the contrary, when a firm does invest “...It gives up the possibility of waiting for new information to arrive that might affect the desirability or timing of the expenditure; it cannot disinvest should market conditions change adversely..." (Dixit and Pyndick (1994) p. 6). In other words, the implementation of a given investment plan carries an opportunity cost equivalent to the exercise of a financial call option. The decision to exercise such an option is irreversible. In fact, although the holder may sell the asset at a later stage, she will not be able to recover the money paid for exercising the option.

Caballero (1991) investigates the impact of uncertainty and irreversibility on investment, highlighting the role that different assumptions on the functional form of adjustment costs and on the degree of competition and returns to scale play in shaping the response of investment to uncertainty. Interestingly, he shows that if we move away from the hypothesis of perfect competition and constant returns to scale towards one of imperfect competition or decreasing returns to scale, the response of investment to uncertainty becomes negative. In this setting, Caballero also shows that the more asymmetric the functional form of adjustment costs is, the more negative the relationship between investment and uncertainty becomes.

However, Pindyck (1993) notes that Caballero's (1991) analysis treats the firm in isolation, describing the effect of a mean-preserving increase in the variance of price, which is exogenous to the firm. However, whilst individual firms' investment and production decisions depend on the price process, they also collectively generate that process. Hence, he analyses the interactions between irreversibility and uncertainty at the industry level by making price and industry output endogenous, and restores the negative relationship between uncertainty and investment. In fact, assuming an industry-wide setting, the possibility of entry of new firms or the expansion of existing ones limits the amount by which price can increase following industry-wide positive shocks. However, with (partial) irreversibility there is no similar mechanism that prevents price from falling under negative shocks. This acts as a disincentive to invest. 
A later contribution by Abel and Eberly (1999) focuses on the ambiguity of the long-run relationship between uncertainty and the average level of capital stock. They analyze the interaction between the user-cost effect and the "hangover" effect on the long-run level of capital stock. The former implies that firms may end up having less capital in the long run than in the absence of irreversibility and uncertainty, since the user cost under irreversibility would be higher than that in the standard case of costless reversibility. The latter effect accounts for the difficulties faced by the firms in divesting capital during economic downturns due to the irreversibility constraint. Accordingly, if the latter effect were to dominate, firms would end up having more capital on average in the long run as compared to the frictionless case. Interestingly, they characterize these opposing effects and show that in the long run either effect may dominate, depending on the values assigned to the parameters in the model.

Given the somewhat inconclusive results provided by this theoretical literature, particularly at the firm level, researchers have resorted to empirical analysis as a way of ascertaining the sign of the investment-uncertainty relationship. Among the most notable of such studies, Guiso and Parigi (1999) investigate the relation between investment and uncertainty using data from a cross-sectional survey representative of the Italian manufacturing sector that reports managers' assessments of the distribution of future demand for their products. They define a measure of idiosyncratic uncertainty closely related to firms' investment decisions and test for a number of theoretical predictions by comparing the amount of investment undertaken by firms with different degrees of market power and factor substitutability, access to credit markets and liquidity constraints. Their evidence strongly suggests a negative relation between uncertainty and investment. However, their cross-section dataset does not allow them to explore the impact of uncertainty and irreversibility on investment dynamics, to which we now turn.

\section{A. Investment Dynamics Under Irreversibility and Uncertainty}

Since the decision to go ahead with an investment project creates a wedge between the full cost of investing and its conventional cost due to the exercising of an option, this is likely to introduce relevant non linearities in the firm's investment behavior. In such a case, a firm's optimal investment is characterized as a trigger policy in which investment occurs only when the gap between the current capital stock and the otherwise optimal one becomes "large enough."

Abel and Eberly (1999) and Bloom (2000) emphasize that, with partial irreversibility, a higher level of uncertainty implies both a higher threshold rate of return to justify positive investment, and a lower threshold required rate of return to justify disinvestment. As the optimal investment policy is characterized by a wider threshold rule, these two factors unambiguously reduce the short-term response of investment to exogenous demand shocks. Bloom (2000) also shows that irreversibility and uncertainty induce richer short-term investment dynamics, with lagged responses to past demand shocks occurring when thresholds are reached.

Bloom, Bond, and Van Reenen (2003) elaborate on the implications of this approach for investment dynamics. They simulate firm-level data from a calibrated model in which firm investment is aggregated over a number of independent plants, subject to idiosyncratic plant-level 
productivity shocks as well as a common firm-level demand shock. One implication of such aggregation is that zero investment observations become rare at the firm level, although the presence of plants within the region of inaction continues to influence the firm-level investment series.

They emphasize the following predictions from their study. First, in the short run, firms facing a higher level of uncertainty should adjust more slowly following a given demand shock, since, according to this theoretical framework, higher uncertainty widens the inaction region. This translates into the intuition that firms may have a greater incentive to adopt a more cautious policy and wait for the arrival of new information before implementing their investment projects and exercising a real option. In addition, they note that there should also be a non-linear effect of demand shocks on investment spending, in a setting where firms invest at multiple plants or in multiple lines of capital. Typically, following a positive demand shock, the line of capital closest to the investment threshold starts adjusting, thus increasing the marginal productivity of the other lines of capital if one assumes supermodularity in their production functions. ${ }^{2}$ As a result, other lines of capital may enter the investment region, therefore reinforcing the initial response of the firm to the demand shock. In principle, this feature operates symmetrically following a negative shock, implying either a convex or concave effect in the firm's response, depending on whether the shock induces investment or disinvestment respectively. Nevertheless, given that as a result of both depreciation and growth we tend to observe positive investment much more commonly than disinvestment, Bloom, Bond, and Van Reenen conclude that the dominant pattern is likely to be a convex response to demand shocks.

Once they have generated investment data, they turn to an empirical analysis to investigate the extent to which these real option effects can be detected using a reduced form error correction model framework ${ }^{3}$. The latter choice is particularly convenient since an ECM specification separates out short-run and long-run dynamics. Furthermore, as the authors note, there is not yet available a structural investment equation useful for testing real option effects on investment decisions.

Their econometric results, using a sample of U.K. manufacturing firms, are similar to those found using the simulated data. In particular, they find evidence of a convex effect of demand shocks on investment decisions. More importantly, they are able to detect evidence of slower adjustment of investment in response to demand shocks at higher levels of uncertainty, consistent with one of the most important predictions from the real option theory.

\footnotetext{
${ }^{2}$ The supermodularity of a production function $F\left(K_{1}, K_{2}, \ldots, K_{N}\right)$ is defined such that $\partial F\left(K_{1}, K_{2}, \ldots, K_{N}\right) / \partial K_{i}$ is increasing in all $K_{j}, j \neq i$. See Dixit (1997).

${ }^{3}$ The following section provides more details on the ECM specification.
} 


\section{ECONOMETRIC SPECIFICATIONS OF INVESTMENT BEHAVIOR}

\section{A. A Baseline Dynamic Model}

The error-correction model, which allows for a flexible adjustment of the capital stock towards its long-run equilibrium value, is a commonly used specification for estimating reduced form empirical investment equations. This makes it particularly suitable for testing the null hypothesis of no effects of uncertainty on investment.

Consider the simplest world with no uncertainty, investment irreversibility or other adjustment costs, and define $k_{i t}$ as the optimal, frictionless level of the logarithm of the capital stock for firm $i$ in period $t$. Then, by defining, respectively, $y_{i t}$ and $j_{i t}$ as logarithms of real output and the user cost of perfectly reversible capital, we can write the optimal capital stock as a function of a quantity variable and a set of price variables embodied in the cost of capital:

$$
k_{i t}=a+y_{i t}-\phi j_{i t}
$$

where $\phi$ is the input elasticity of substitution. It can be shown that this expression for the level of capital represents the solution to the static profit maximization problem of a firm operating with a constant elasticity of substitution (CES) technology and constant returns to scale; for $\phi$ equal to unity, (1) encompasses the case of a Cobb-Douglas production function (see, for example, Bond and Van Reenen (2003)).

However, firms have to bear some costs during the transition to a new equilibrium level of capital, typically due to the installation of new equipment, the resulting dislocation of ongoing productive activities, the need for training the workforce to use the new equipment and the burden imposed upon the managerial and administrative skills of existing planning staff. In the presence of such adjustment costs, the actual capital stock does not adjust immediately to changes in the optimal frictionless level. An econometric specification that captures dynamic adjustment of the capital stock is an autoregressive-distributed lag (ADL) model such as:

$$
\begin{aligned}
k_{i t}= & \alpha_{0}+\alpha_{1} k_{i, t-1}+\alpha_{2} k_{i, t-2}+\beta_{0} y_{i t}+\beta_{1} y_{i, t-1}+\beta_{2} y_{i, t-2} \\
& +\gamma_{0} j_{i t}+\gamma_{1} j_{i, t-1}+\gamma_{2} j_{i, t-2}+\epsilon_{i t} .
\end{aligned}
$$

Bean (1981) first introduced a now widely used specification of the investment equation that separates out short- and long-run dynamics. Assuming also that variation in the cost of capital can be accounted for by additive year-specific effects $\left(\mu_{t}\right)$ and firm-specific effects $\left(\eta_{i}\right)$, then a convenient reparameterization of (2) gives the error correction $\operatorname{model}^{4}$ :

${ }^{4}$ Cf. Bond and others (2003), Bond, Harhoff, and Van Reenen (1999), and Mairesse, Bronwyn, and Mulkay (1999) for recent applications to micro data. 


$$
\begin{aligned}
\Delta k_{i t}= & \mu_{t}+\left(\alpha_{1}-1\right) \Delta k_{i, t-1}+\beta_{0} \Delta y_{i t}+\left(\beta_{0}+\beta_{1}\right) \Delta y_{i, t-1} \\
& -\left(1-\alpha_{1}-\alpha_{2}\right)(k-y)_{i, t-2} \\
& +\left[\beta_{0}+\beta_{1}+\beta_{2}-\left(1-\alpha_{1}-\alpha_{2}\right)\right] y_{i, t-2} \\
& +\eta_{i}+\varepsilon_{i t} .
\end{aligned}
$$

The above model allows for rich short-run dynamics and incorporates a feedback mechanism towards the long-run target on the same lines as that proposed by Davidson, Hendry, Srba and Yeo (1978) and Hendry (1980).

\section{B. An Augmented Error-Correction Model}

In the remainder of this section, we show how the baseline specification as given by (3) can be extended for the purpose of our analysis. Under partial irreversibility, the logarithm of the actual capital stock $\left(k_{i t}\right)$ and the hypothetical frictionless optimum $\left(k_{i t}^{*}\right)$ may differ, and need not be equal on average in the long run. In this setting we can exploit a result found by Bloom (2000) according to which the long-run growth rate of a firm's capital stock under partial irreversibility and its hypothetical value under costless reversibility will be equal. Therefore, it follows that:

$$
k_{i t}=k_{i t}^{*}+\varphi_{i t}
$$

with $k_{i t}$ and $k_{i t}^{*}$ cointegrated, so that $\varphi_{i t}$ is a stationary error term. This relation does not impose the restriction that $\varphi_{i t}$ should be a mean-zero process since the average levels of these two notions of the capital stock may be different.

Combining (1), (2), and (4), we obtain an ECM specification analogous to (3) that allows us to formulate a model for the dynamics of the actual capital stock based on its much simpler frictionless hypothetical value.

Following Bloom, Bond, and Van Reenen (2003), our specification tests for the non-linear response of investment rates to demand shocks predicted by the partial irreversibility model by including an additional quadratic term $\left(\Delta y_{i t}\right)^{2}$; and tests for the predicted effect of uncertainty on the short-run response of investment rates to demand shocks by including an additional interaction term $\left(\sigma_{i t} \Delta y_{i t}\right)$, where $\sigma_{i t}$ is a measure of the uncertainty faced by firm $i$ at time $t$. These additional terms, together with the approximation that $\Delta k_{i t} \approx I_{i t} / K_{i, t-1}-\delta_{i}$, where $\delta_{i}$ is a firm-specific depreciation rate, suggest the following model of the investment rate: 


$$
\begin{aligned}
\left(\frac{I_{i t}}{K_{i, t-1}}\right)= & \mu_{t}+\omega_{0}\left(\frac{I_{i, t-1}}{K_{i, t-2}}\right)+\omega_{1} \Delta y_{i t}+\omega_{2} \Delta y_{i, t-1}+\omega_{3}\left(\Delta y_{i t}\right)^{2} \\
& +\omega_{4}\left(\sigma_{i t} \Delta y_{i t}\right)+\theta(k-y)_{i, t-1} \\
& +\omega_{5} \sigma_{i, t-1}+\omega_{6} y_{i, t-2}+\omega_{7}\left(\frac{C_{i t}}{K_{i, t-1}}\right)+\eta_{i}+\varepsilon_{i t}
\end{aligned}
$$

with $I_{i t}$ being the gross investment of firm $i$ at time $t$ and $K_{i t}$ its end-of-period capital stock. As noted above, the analysis of investment under uncertainty with partial irreversibility of investment decisions suggests $\omega_{4}<0$. For firms undertaking positive investment this analysis also predicts a convex response of the investment rate to demand shocks, which implies $\omega_{3}>0$. Our specification also allows for a long-run effect of uncertainty $\left(\sigma_{i, t-1}\right)$ on the level of the capital stock, so that possible long-run effects would not be picked up by the interaction term $\left(\sigma_{i t} \Delta y_{i t}\right)$.

To allow for a possible interaction between the real and financial decisions of firms, the ratio of cash flow to the beginning-of-period capital stock $\left(C_{i t} / K_{i, t-1}\right)$ is also included in the model, along the lines suggested by previous studies. ${ }^{5}$ Although this is not the main focus of our paper, we control for cash flow to avoid the possibility that any uncertainty effect that we identify may simply be proxying for omitted liquidity effects.

In the specification above, the parameter $\theta$ represents the speed of adjustment through which the investment rate responds to a disequilibrium in the long-run relationship between capital and output. A negative value of the parameter $\theta$ is required for the estimated dynamics to be consistent with 'error correcting' behavior, so that a capital stock above (below) its desired level is associated with lower (greater) future investment. With reference to the parameter $\omega_{6}$, in the context of a CES production function with $\phi \neq 1$, the coefficient on the lagged level of output tests the long-run constant returns to scale restriction $\left(\beta_{0}+\beta_{1}+\beta_{2}\right) /\left(1-\alpha_{1}-\alpha_{2}\right)=1$ (see (3)), although if the production function is Cobb-Douglas then there should be a long-run proportional relationship between capital and output regardless of the returns to scale.

Finally, in the error structure of (5), $\varepsilon_{i t}$ contains residual components of $\varphi_{i t}$ as in (4) that are not captured by the dynamic specification of (5). The unobserved firm-specific effects $\left(\eta_{i}\right)$ allow for the variation across firms in the price elasticity of product demand, the rate of depreciation, and more generally in the user cost of capital $\left(j_{i t}\right)$. The time dummies $\left(\mu_{t}\right)$ allow for variation over time in the user cost of capital, and for other aggregate shocks whose effects on investment are common to all firms. The inclusion of time dummies also addresses concerns about spurious correlation between investment and uncertainty that may arise from fluctuations in measured uncertainty over the business cycle.

\footnotetext{
${ }^{5}$ See, for example, Bond and Van Reenen (2003) and Hubbard (1998).
} 


\section{DATA DESCRIPTION}

\section{A. Stylized Facts}

The dataset we use comes from the high quality Survey of Investment in Manufacturing (SIM) conducted annually by the Bank of Italy. The data cover a random sample of firms representative of the Italian manufacturing sector from 1984 to $1998 .{ }^{6}$ Table A.1 in the appendix provides a detailed breakdown of the sample according to the type of ownership, location, industry, and the size of firms surveyed.

The median firm size - 266 employees - is relatively small, and 51 percent of the firms in the sample employ between 100 and 499 employees. Most firms belong to industrial holdings, while only a tiny proportion of them is quoted on the stock market in the years when such information is available. $^{7}$

In order to investigate investment dynamics at the micro level, we have merged the information from this source with that from a balance-sheet database. ${ }^{8}$ Matching this additional information entails the loss of approximately one-third of the initial 14,873 observations. Furthermore, we drop all observations related to state-owned firms and restrict the sample to those firms for which we have at least four consecutive years of data, after constructing the appropriate lagged variables required for the empirical analysis. In Table A.1, we compare the resulting usable sample with the original survey data. Overall, the composition of the sample does not change substantially and one can see that, based on a number of criteria, the final sample appears to inherit the main properties of the survey data. Tables A.2 and A.3 in the appendix provide information on the balance of the panel and further descriptive statistics for the sample.

As discussed earlier, a basic prediction from the threshold-based models used to describe irreversible investment decisions under uncertainty is that we should observe zero-investment episodes in capital expenditures data, corresponding to the inaction region. However, the detection of such a pattern is often masked by aggregation of underlying data across capital expenditures on different types of assets, as well as across investment at different production locations.

This important feature of investment data has already been documented by Doms and Dunne (1994, 1999) and Caballero, Engel and Haltiwanger (1995) for the US; by Attanasio, dos Reis, and Pacelli (2000) for the U.K.; by Nilsen and Schiantarelli (2000) for Norway; by Bigsten and others (1999), and Pattillo (1998) for Africa; and, finally, by Gelos and Isgut (1999) for Latin America.

\footnotetext{
${ }^{6}$ See the appendix for a more detailed description of the dataset.

${ }^{7}$ Only 3.9 percent of the firms sampled in 1997 are listed.

${ }^{8}$ Again the appendix provides more details on this dataset.
} 
With reference to our dataset, we provide some descriptive evidence that appears to confirm the above findings. In Table 1 we report the frequency of observations for which zero investment is reported, both in total and for different types of assets (buildings, plant and machinery, and transportation). The breakdown by assets allows us to assess the importance of aggregation across different types of investment goods in concealing zero investment episodes in the firm-level data. The data refer to all the firms in our sample from 1991 to 1998, since the breakdown is not available for earlier years. We also report the frequency of observations for which zero disinvestment (i.e. sales of capital goods) is reported, although here the breakdown by asset type is not available.

Taking employment as a proxy for firm size, it may be noticed that whilst years with zero total investment are rare, the frequency of zero investment episodes tends to be higher for smaller firms. The frequency of zero investment episodes is also higher when considering investment data disaggregated by type of asset. The frequency of zero investment years for buildings and transportation approaches 50 percent for the smallest class of firms. Years with zero disinvestment are much more common than years with zero investment, although observations with zero disinvestment also become rarer as we consider larger firms.

To illustrate the effect of aggregation across different production locations, we report in Table 2 the frequency of zero investment and disinvestment episodes broken down according to the number of plants operated by each firm. Although this table refers only to selected years, for which information on the number of plants operated by each firm is available, it appears to confirm the previous insight that the frequency of zero investment episodes tends to be higher for smaller firms with fewer production units, where aggregation over different assets and plants is likely to be less important. These preliminary findings suggest that the investment behavior of the firms in our sample may be consistent with the predictions of threshold-based policies.

Table 1. Frequency of Zero Investment and Disinvestment Episodes (Breakdown by No. of Employees)

\begin{tabular}{|c|c|c|c|c|c|c|}
\hline Employees & Buildings & Machinery & Transport & Total & Total & Total \\
\hline & & & & Investment & Disinvestment & Investment and \\
\hline & & & & & & Disinvestment \\
\hline $50-99$ & 53.30 & 4.95 & 41.75 & 4.17 & 45.52 & 3.30 \\
\hline $100-199$ & 41.19 & 1.38 & 27.72 & 0.75 & 36.60 & 0.61 \\
\hline $200-499$ & 27.94 & 0.91 & 17.49 & 0.38 & 31.07 & 0.38 \\
\hline $500-999$ & 23.03 & 0.00 & 15.44 & 0.00 & 27.64 & 0.00 \\
\hline$\geq 1,000$ & 12.87 & 0.00 & 9.12 & 0.00 & 21.44 & 0.00 \\
\hline
\end{tabular}

Note: Data refer to the period from 1991 to 1998 and cover 2,682 observations. 
Table 2. Frequency of Zero Investment and Disinvestment Episodes (Breakdown by No. of Plants)

\begin{tabular}{|c|c|c|c|c|c|c|}
\hline Plants & Building & Machinery & Transport & Total & Total & Total \\
\hline & & & & Investment & Disinvestment & Investment and \\
\hline & & & & & & Disinvestment \\
\hline 1 & 38.96 & 2.19 & 23.75 & 1.46 & 35.57 & 1.20 \\
\hline 2 & 26.49 & 1.32 & 17.55 & 1.32 & 32.58 & 1.12 \\
\hline 3 & 26.35 & 0.00 & 13.51 & 0.00 & 31.36 & 0.00 \\
\hline$\geq 4$ & 16.67 & 0.00 & 7.41 & 0.00 & 23.53 & 0.00 \\
\hline
\end{tabular}

Note: Data refer to the period from 1992 to 1995 only and cover 1,689 observations.

\section{MeAsuring UnCERTAinty}

Our measure of uncertainty is based on the accuracy of firms' forecasts of their own investment spending one year ahead. The idea is that if a firm faces no uncertainty, it would know its future investment level, and these forecast errors would be zero. The more uncertain the environment in which the firm operates, the more likely it is that next period's investment will turn out to be different from the firm's current forecast. This will be reflected in a higher variance of the firm's forecast errors. We therefore construct a measure of the firm's uncertainty based on the ex-post errors in the one-year ahead investment forecasts of firms' managers, as reported in the Survey of Investment in Manufacturing. However, since the forecast errors for the level of investment are also likely to be affected by firm size, we consider a measure of the forecast error normalized by the (known) level of the firm's existing capital stock.

In particular, let $E_{i, t-1}\left(I_{i t}\right)$ be the forecast reported by firm $i$ at time $t-1$ for its investment spending at time $t$. Dividing by the firm's capital stock at time $t-1$, we obtain $E_{i, t-1}\left(\frac{I_{i t}}{K_{i, t-1}}\right)$ or the one-year ahead expected investment rate. Then using the same firm's reported investment spending one period later $\left(I_{i t}\right)$, the ex-post forecast error $(f e)_{i t}$ is:

$$
(f e)_{i t}=\frac{I_{i t}}{K_{i, t-1}}-E_{i, t-1}\left(\frac{I_{i t}}{K_{i, t-1}}\right)
$$

To ensure that positive as well as negative forecast errors are equally weighted, (6) can be squared to obtain:

$$
(f e)_{i t}^{2}=\left[\frac{I_{i t}}{K_{i, t-1}}-E_{i, t-1}\left(\frac{I_{i t}}{K_{i, t-1}}\right)\right]^{2}
$$


The variance of these forecast errors can be estimated for alternative sample periods. At one extreme, we could use the variance of the forecast errors computed using all the available observations for a particular firm:

$$
\sigma_{i}^{2}=\frac{1}{T} \sum_{t=1}^{T}(f e)_{i t}^{2}
$$

where $T$ is the number of years that forecast errors for firm $i$ are observed in the sample. However, using (8) as the measure of uncertainty in our empirical investment equations would not allow us to investigate the long-run effects of uncertainty on the level of the capital stock whilst controlling for unobserved firm-specific effects, since there is no variation over time in this measure. The restriction that the uncertainty in each firm's environment is constant over time may also be unduly restrictive. At the other extreme, we could simply attempt to use $(f e)_{i t}^{2}$ as a measure of uncertainty at time $t$. In this case, however, other concerns would arise due to the fact that an estimate of the variance based on only a single observation would be very noisy.

In order to strike a balance between these conflicting concerns, our main results are reported using the following rolling measure of uncertainty:

$$
\sigma_{i t}^{2}=\frac{1}{t} \sum_{s=1}^{t}(f e)_{i s}^{2}
$$

This measure is time-varying and therefore allows us to explore the long-run impact of uncertainty on capital accumulation. In addition, the forecast error variance is estimated using a minimum number of observations. In the empirical analysis, we use an estimated rolling variance of the forecast errors based on at least 4 observations. In terms of (9), this is equivalent to requiring $t \geq 4$. We checked that similar results were obtained using rolling variance measures based on different numbers of observations.

Unlike some previous measures used in the empirical literature, (9) is not related to any specific source of uncertainty, and is more likely to reflect uncertainty about a range of factors that may influence capital expenditure decisions. For example, firms face uncertainty related to wages, prices, costs of raw materials, exchange rates, technology, consumer tastes and government policies. Importantly, in contrast with much previous research ${ }^{9}$, our proxy is based on the assessment of decision makers who have informed knowledge and bear a direct responsibility in the planning and implementation of a firm's investment projects. In this respect, our measure is similar to that employed by Guiso and Parigi (1999), who derived a proxy based on the managers' assessment of future demand growth. However, their measure was not time-varying and, therefore,

${ }^{9}$ See Carruth, Dickerson, and Henley (2000) for a survey of the most common measures of uncertainty employed in the investment literature. 
could only be used in a cross-sectional framework.

Before turning to the econometric analysis, in Tables 3 and 4 we present some descriptive statistics on the uncertainty measure and how it relates to some observable features in our sample such as firm size and the industrial sector in which a firm operates. As Table 3 shows, at least on average the realized investment rates are reasonably close to firms' ex ante expectations. This is also true for sub-samples of firms defined by whether our measure of uncertainty is relatively high or relatively low. Firms facing lower uncertainty tend to have higher investment rates than firms facing higher uncertainty, and this is reflected in their ex ante expectations. It is also interesting to note that this feature of our data is consistent with that reported by Guiso and Parigi (1999), who show that in their sample the low-uncertainty firms expect to invest more than the high-uncertainty firms, in proportion to their current capital stock.

Table 4 reports that firms facing relatively high uncertainty according to our measure are more likely to be found in the sectors producing electrical goods, transport, machinery, leather and footwear, and other manufacturing goods. The smallest firms in our sample - that is, those employing 50-99 employees - are more likely to be in the high uncertainty group. However, there is no clear relation with firm size among firms with 100 or more employees.

Table 3. Investment and Expected Investment Rates

\begin{tabular}{ccccc}
\hline Variable & & $\begin{array}{c}\text { Low } \\
\text { Uncertainty }\end{array}$ & $\begin{array}{c}\text { High } \\
\text { Uncertainty }\end{array}$ & $\begin{array}{c}\text { Total } \\
\text { Sample }\end{array}$ \\
\hline$\left(\frac{I_{i t}}{K_{i, t-1}}\right)$ & & & & \\
& Mean & 0.1174 & 0.0749 & 0.0962 \\
& Median & 0.0982 & 0.0613 & 0.0767 \\
$E_{i, t-1}\left(\frac{I_{i t}}{K_{i, t-1}}\right)$ & & & & \\
& Mean & 0.1169 & 0.0706 & 0.0937 \\
& Median & 0.0942 & 0.0598 & 0.0766 \\
\hline
\end{tabular}

Note: The column "Low Unc." ("High Unc.”) refers to the subsample with measured uncertainty below (above) the sample median.

Overall, this indicates that idiosyncratic firm-level variation in uncertainty is potentially important, as variation in uncertainty is not well explained by sector or firm size. ${ }^{10}$ Firms with a higher level of measured uncertainty are found to invest less than those with a lower level of measured uncertainty. This suggests that our measure of uncertainty contains some information that is relevant for understanding investment. The nature of this relationship is explored more thoroughly in the next section.

${ }^{10}$ Guiso and Parigi (1999) also reported that there was no clear relationship between their firm-level measure of uncertainty and a set of observable firm characteristics. The only exception was whether firms were privately-owned or state-owned. In our sample, the latter group is not present. 
Table 4. Firms with Low and High Uncertainty

\begin{tabular}{lll}
\hline Industrial sector & $\begin{array}{l}\text { Low } \\
\text { Uncertainty }\end{array}$ & $\begin{array}{l}\text { High } \\
\text { Uncertainty }\end{array}$ \\
\hline Metallurgy & 53.42 & 46.58 \\
Nonmetallic mineral products & 58.59 & 41.41 \\
Chemical products & 48.66 & 51.34 \\
Machinery & 46.32 & 53.68 \\
Electrical goods & 42.86 & 57.14 \\
Trains, ships, planes, and motor vehicles & 45.24 & 54.76 \\
Food products, beverage, and tobacco & 54.72 & 45.28 \\
Clothing and textiles & 50.68 & 49.32 \\
Leather and footwear & 45.40 & 54.60 \\
Timber and furniture & 47.83 & 52.17 \\
Paper, printing, and publishing & 52.17 & 47.83 \\
Rubber and plastic goods & 50.30 & 49.70 \\
Other manufacturing goods & 42.58 & 57.42 \\
& & \\
Size & & \\
50-99 employees & 46.21 & 53.79 \\
100 or more employees & 50.00 & 50.00 \\
\hline
\end{tabular}

Note: The column "Low Unc." ("High Unc.”) refers to the frequency of the observations for which our measure of uncertainty is smaller (greater) than the overall sample median.

\section{ECONOMETRic AnAlysis}

\section{A. Estimation}

The empirical specification given by (5) requires the estimation of a dynamic panel data model. Arellano and Bond (1991) have developed a general method of moments (GMM) estimator to account for the presence of lagged dependent variables, the endogeneity of current-dated explanatory variables and for unobserved firm-specific effects. Their first-differenced GMM estimator relies on equations in first differences from which firm-specific effects are eliminated; regressors can then be instrumented using lagged endogenous variables provided that the time-varying component of the model's residuals exhibits limited serial correlation. Arellano and Bond (1991) also provide useful tests for inspecting the degree of serial correlation in the residuals.

Blundell and Bond (1998) noted that in dynamic panel data models where the individual series are reasonably persistent and where the number of time-series observations is relatively small, lagged levels of the series provide only weak instruments for variables in first differences and the resulting first-differenced GMM estimates exhibit large finite sample biases. Their extended GMM estimator makes use of lagged differences of endogenous variables as instruments for equations in levels, in addition to lagged levels of endogenous variables as instruments for equations in first 
differences (see also Arellano and Bover (1995)). Monte Carlo simulations have shown that this extended GMM estimator yields substantial gains in the precision of parameter estimates and potentially dramatic reductions in the finite sample bias, provided that these additional instruments are valid. This can be tested using standard tests of overidentifying restrictions.

Monte Carlo simulations have also shown that the asymptotic standard errors of the efficient two-step version of this GMM estimator are affected by a finite sample bias that can result in a misleading inference. Windmeijer (2000) analyses this problem and proposes a finite sample correction. Importantly, we apply this correction to the variance of the two-step GMM estimator, so that the two-step estimates can be used to gauge the robustness of the results provided by the one-step GMM estimator.

\section{B. Empirical Results and Their Policy Implications}

Our preferred results - robust to different choices of the instrument set - treat current sales as predetermined, with the precise set of instruments reported in detail in the note to the tables. The validity of the instruments is assessed by means of a Sargan test of overidentifying restrictions.

While we report the whole set of results based on this extended GMM estimator, we have also checked their robustness against alternative estimators such as Within Groups, OLS and first-differenced GMM.

The GMM one-step and two-step results with heteroskedasticity-robust standard errors are reported in Tables 5 and 6, respectively. They have been computed using DPD98 for Gauss, with a modification provided by Windmeijer (2000) for computing the corrected variance matrix.

Before presenting the results, it is interesting to note that cash flow was not found to be statistically significant in any of the empirical specifications we considered, nor was it informative as an instrument. This result, pointing to a lack of liquidity effects for the firms sampled, is consistent with previous evidence on Italian company data. ${ }^{11}$ Furthermore, the hypothesis of constant returns to scale was not rejected by the data at conventional significance levels, and is imposed throughout. Overall, diagnostic test results are very satisfactory, offering no evidence of second-order serial correlation in the first-differenced residuals and the Sargan statistic does not reject the overidentifying restrictions.

In reporting our results we start from the simplest linear specification of the ECM model and comment on various extensions of it. Overall, the results using the one-step and two-step GMM estimators are very similar. Column (1) reports estimates for the most basic specification that does not take into account non linearity $\left(\Delta y_{i t}\right)^{2}$ nor the interaction term between real sales growth and uncertainty $\left(\sigma_{i t}^{2} \Delta y_{i t}\right)$. The point estimates on current and lagged growth in real sales are along the lines of the results reported in previous studies (see, for example, Bond, Harhoff, and Van Reenen (1999). The coefficient on the error correction term, negatively signed and statistically significant, is consistent with error-correcting behavior.

${ }^{11}$ See, among others, Bettoni (2000) and Carpenter and Rondi (2000). 
In column (2) the inclusion of the squared-sales growth-rate term allows us to test the null hypothesis of a linear accelerator effect against the alternative of non-linear dynamics predicted by the real options model. The coefficient on this quadratic term is both large (one-step point estimate of 0.34 ) and significantly different from zero at conventional levels, indicating a convex response of investment to demand shocks.

In column (3), the inclusion of the uncertainty interaction term allows us to test the null hypothesis of a common response of investment to demand shocks against the alternative of a heterogeneous response for firms that face different levels of measured uncertainty. Again, from our results this null hypothesis is clearly rejected. Uncertainty exerts a powerful impact on firms' short-run investment behavior, with a weaker response to demand shocks at higher levels of uncertainty, exactly the effect predicted by the partial irreversibility model. Indeed, the coefficient on the interaction term is large in absolute value (one-step point estimate of 0.92 ) and is significantly different from zero at conventional levels of significance.

Column (4) allows for a further effect of uncertainty on the long-run level of the capital stock. While the relevance of the short-run effect on investment dynamics, as proxied by the interaction term is confirmed, the long-run effect of uncertainty is found to be both small and statistically insignificant. Finally, in the last column we re-estimate the investment equation allowing only for the long-run effect of uncertainty, but again we do not identify any significant long-run effect.

Overall, these findings are consistent with those reported by Bloom, Bond, and Van Reenen (2003) on a sample of UK manufacturing firms, using share price volatility as a measure of uncertainty. The theory of investment under partial irreversibility predicts that firms' short-term investment policies become less responsive to demand shocks at higher levels of uncertainty since a more cautious approach has a higher pay-off. This theoretical prediction is supported by our empirical analysis. The policy implications of this result are potentially important: investment reacts more sluggishly to policy interventions when firms operate in a more uncertain environment. The level of uncertainty is therefore important in predicting the short-run effects of policy interventions. This result on the effect of uncertainty on investment dynamics may also shed light on why empirical estimates of mainstream investment equations often fail to perform satisfactorily: failure to include interactions between uncertainty and output growth, and non-linear terms in output growth, in standard empirical models of the investment rate may account for unstable parameter estimates across different sample periods. 
Table 5. Investment Equations:

One-Step Results

\begin{tabular}{|c|c|c|c|c|c|}
\hline$I_{i t} / K_{i, t-1}$ & (1) & (2) & (3) & (4) & $(5)$ \\
\hline$\Delta y_{i t}$ & $\begin{array}{c}0.1163 \\
0.0304\end{array}$ & $\begin{array}{c}0.1028 \\
0.0316\end{array}$ & $\begin{array}{c}0.2469 \\
0.0588\end{array}$ & $\begin{array}{c}0.2475 \\
0.0589\end{array}$ & $\begin{array}{c}0.1142 \\
0.0171\end{array}$ \\
\hline$\Delta y_{i, t-1}$ & $\begin{array}{c}0.1456 \\
0.0239\end{array}$ & $\begin{array}{c}0.1402 \\
0.0237\end{array}$ & $\begin{array}{c}0.1364 \\
0.0175\end{array}$ & $\begin{array}{c}0.1359 \\
0.0175\end{array}$ & $\begin{array}{c}0.1394 \\
0.0177\end{array}$ \\
\hline$(k-y)_{i, t-2}$ & $\begin{array}{c}-0.1354 \\
0.0273\end{array}$ & $\begin{array}{c}-0.1335 \\
0.0271\end{array}$ & $\begin{array}{c}-0.1356 \\
0.0203\end{array}$ & $\begin{array}{c}-0.1351 \\
0.0205 \\
\end{array}$ & $\begin{array}{c}-0.1383 \\
0.0205 \\
\end{array}$ \\
\hline$\Delta y_{i t}^{2}$ & - & $\begin{array}{c}0.3376 \\
0.1281\end{array}$ & $\begin{array}{c}0.3282 \\
0.1215\end{array}$ & $\begin{array}{c}0.3296 \\
0.1222\end{array}$ & $\begin{array}{c}0.2875 \\
0.1189\end{array}$ \\
\hline$\sigma_{i t}^{2} * \Delta y_{i t}$ & - & - & $\begin{array}{c}-0.9209 \\
0.3862\end{array}$ & $\begin{array}{c}-0.9279 \\
0.3870\end{array}$ & - \\
\hline$\sigma_{i, t-1}^{2}$ & - & - & - & $\begin{array}{c}0.0199 \\
0.0545\end{array}$ & $\begin{array}{c}0.0025 \\
0.0544\end{array}$ \\
\hline & & & & & \\
\hline Sargan (p) & 0.34 & 0.37 & 0.46 & 0.44 & 0.34 \\
\hline LM2 (p) & 0.71 & 0.83 & 0.77 & 0.76 & 0.86 \\
\hline Observations & 4,192 & 4,192 & 4,192 & 4,192 & 4,192 \\
\hline Firms & 564 & 564 & 564 & 564 & 564 \\
\hline
\end{tabular}

Notes: Asymptotically robust standard errors are reported below the coefficients; estimation by GMM-SYSTEM using DPD98 package one-step results; full set of time-dummies included, results available upon request; 'Sargan' is a Sargan-Hansen test of overidentifying restrictions; 'LM2' is the test for the absence of 2nd-order serial correlation in the first-differenced residuals, distributed $\mathrm{N}(0,1)$ under the null (p-value reported); in column (1) instruments are $I_{i, t-2} / K_{i, t-3}, I_{i, t-3} / K_{i, t-4}, y_{i, t-1}$, $y_{i, t-2}, y_{i, t-3},(k-y)_{i, t-2},(k-y)_{i, t-3}$ in the differenced equations, $\Delta\left(\frac{I_{i, t-1}}{K_{i, t-2}}\right)$ and $\Delta y_{i, t}$ in the levels equations; in column (2) we also include $\Delta y_{i, t-1,}^{2} \Delta y_{i, t-2}^{2}, \Delta y_{i, t-3}^{2}$, in the set of instruments for the differenced equations and, in column (3) to (5), we further include $\sigma_{i, t-2}^{2}, \sigma_{i, t-3}^{2}, \sigma_{i, t-4}^{2}$. 
Table 6. Investment Equations:

Two-Step Results

\begin{tabular}{|c|c|c|c|c|c|}
\hline$I_{i t} / K_{i, t-1}$ & (1) & (2) & (3) & (4) & $(5)$ \\
\hline$\Delta y_{i t}$ & 0.1030 & 0.0992 & 0.2187 & 0.2197 & 0.0992 \\
\hline$\Delta u_{i}$ & $\begin{array}{c}0.0255 \\
0.1228\end{array}$ & $\begin{array}{c}0.0265 \\
0.1210\end{array}$ & $\begin{array}{c}0.0534 \\
0.1160\end{array}$ & $\begin{array}{c}0.0531 \\
0.1157\end{array}$ & $\begin{array}{c}0.0164 \\
0.1161\end{array}$ \\
\hline$\Delta y_{i, t-1}$ & $\begin{array}{l}0.12219 \\
0.0219\end{array}$ & 0.0218 & 0.0168 & 0.0169 & $\begin{array}{l}0.0166 \\
0.0106\end{array}$ \\
\hline$(k-y)_{i, t-2}$ & -0.1314 & -0.1277 & -0.1158 & -0.1155 & -0.1194 \\
\hline$\Delta y_{i t}^{2}$ & - & 0.2258 & 0.2295 & 0.2316 & 0.1923 \\
\hline$\sigma_{i t}^{2} * \Delta y_{i t}$ & - & - & -0.8247 & -0.8331 & - \\
\hline$\sigma_{i, t-1}^{2}$ & - & - & - & $\begin{array}{c}0.0115 \\
0.0477\end{array}$ & $\begin{array}{c}0.0054 \\
0.0479\end{array}$ \\
\hline & & & & & \\
\hline Sargan (p) & 0.34 & 0.37 & 0.46 & 0.44 & 0.34 \\
\hline LM2 (p) & 0.74 & 0.78 & 0.64 & 0.64 & 0.71 \\
\hline Observations & 4,192 & 4,192 & 4,192 & 4,192 & 4,192 \\
\hline Firms & 564 & 564 & 564 & 564 & 564 \\
\hline
\end{tabular}

Notes: Asymptotically robust standard errors are reported below the coefficients; estimation by GMM-SYSTEM using DPD98 package two-step results as modified by Windmeijer (2000); full set of time-dummies included, results available upon request; 'Sargan' is a Sargan-Hansen test of overidentifying restrictions; 'LM2' is the test for the absence of 2nd-order serial correlation in the first-differenced residuals, distributed $\mathrm{N}(0,1)$ under the null (p-value reported); in column (1) instruments are $I_{i, t-2} / K_{i, t-3}$, $I_{i, t-3} / K_{i, t-4}, y_{i, t-1}, y_{i, t-2}, y_{i, t-3},(k-y)_{i, t-2},(k-y)_{i, t-3}$ in the differenced equations, $\Delta\left(\frac{I_{i, t-1}}{K_{i, t-2}}\right)$ and $\Delta y_{i, t}$ in the levels equations; in column (2) we also include $\Delta y_{i, t-1,}^{2} \Delta y_{i, t-2,}^{2} \Delta y_{i, t-3,}^{2}$ in the set of instruments for the differenced equations and, in column (3) to (5), we further include $\sigma_{i, t-2}^{2}, \sigma_{i, t-3}^{2}, \sigma_{i, t-4}^{2}$.

\section{CONCLUSION}

In this paper, we have tested the predictions of a model of investment under partial irreversibility using data on Italian firms. Following Bloom, Bond, and Van Reenen (2003), we emphasize that these models predict a slower response of investment to demand shocks at higher levels of uncertainty, as well as a strictly convex response of investment to current demand shocks. We use data on firms' expectations of future investment, available in the Bank of Italy Survey of Investment in Manufacturing, to construct a measure of uncertainty based on these firms' forecast errors. We find that current investment responds more slowly to real sales growth for firms that face a higher level of uncertainty, and we also find evidence of the predicted nonlinear response of investment to real sales growth.

These findings have important implications for the effects of monetary and fiscal policies on firms' investment spending, suggesting that a given demand stimulus will tend to have weaker effects in the short run at higher levels of uncertainty. Our results suggest that these heterogeneous and nonlinear dynamics may also be important in developing stable econometric models of 
investment for more aggregated data. Finally, the effect of uncertainty on capital accumulation in the long run, which is theoretically ambiguous in this class of models, is not clearly identified from our empirical analysis. Whether this reflects the limited time-series variation in our measure of uncertainty, or is a deeper feature of investment behavior, remains an important question for future research. 


\section{APPEndix}

The dataset employed in this paper has resulted from the merging of two sources: the Bank of Italy Survey of Investment in Manufacturing (SIM) and the Company Accounts Data Service (CADS).

\section{A. Survey of Investment in Manufacturing (SIM)}

The Bank of Italy carries out an annual survey of realized and planned investments in fixed capital among a randomly-selected sample of about 1,000 firms representative of the manufacturing industry. While the basic version of the survey was first carried out in the 1970s, results have been available in electronic format since the 1984 edition. The relevant population refers to businesses with more than 50 employees and operating in the manufacturing industry, with the exclusion of the energy sector, which has been surveyed only since 1999. The unit surveyed is the firm and the sample is stratified on the basis of firm size, geographical location and sector of activity, according to the joint frequency distribution compiled by the Italian National Statistics Institute (the ISTAT). While the number of employees is taken as the measure of firm size, the sector of activity refers to the ISTAT three-digit ATECO-91 classification, consistent with the NACE-CLIO international standards. The geographical location is taken to be the region in which the firm has established its legal headquarters.

Despite its name, the survey collects data on a number of variables besides investment: in addition to indicating the reasons for not fully realizing their investment plans, firms are asked about employment figures and their expected growth; the number of effective hours worked; their total and export turnover; and the change in the price of the goods they produce. In recent years, firms have also been surveyed about their expected turnover, the expected change in their goods' prices, and their ownership structure, and they have been asked to report whether they are listed on a stockmarket or belong to a holding. For selected years, data on the number of plants operated by each firm are also available. Starting from 1992, an additional section has been added to the survey. Firms have been surveyed about e-commerce (1999), labor firing costs (1998), and capital stock and foreign investments (1997), pricing policies and market structure (1996), technological change (1995), wage bargaining (1994), product demand expectations (1993), and ownership structure (1992).

The survey is carried out by means of interviews by highly trained Bank of Italy officials who have normally established long-term relationships with firms' managers. Questionnaires are sent out by the end of December of the year the survey refers to and are then collected by April of the following year at the latest. Responses are carefully scrutinized by specialized teams within the Bank. These teams also check with the firms on any possible inconsistencies arising from their responses. In the survey, firms are also asked whether a major corporate event has occurred in the year (a merger or an acquisition etc.) and to report data on a basis consistent with the previous year. 
The main results from the survey are published each year in the Bank of Italy's Annual Report. So far the resulting dataset has fed into several studies on the structure and the behavior of the Italian manufacturing sector ${ }^{12}$.

\section{B. Company Accounts Data Service (CADS)}

The CADS is provided by Centrale dei Bilanci, an institution owned by the Bank of Italy and a consortium of commercial banks. The dataset comprises roughly 800 items from income statements, balance-sheets and other non accounting sources for about 40,000 financial and non-financial firms. The data is aggregated in order to ensure comparability across firms and is available on an annual basis since 1981. The sample is not randomly drawn since a firm enters the dataset after applying for a loan from one of the banks owning Centrale dei Bilanci.

\section{Estimation of Capital Stocks}

Capital stocks have been estimated through a perpetual inventory method:

$$
P_{t}^{I} K_{t}=(1-\delta) P_{t-1}^{I} K_{t-1}\left(P_{t}^{I} / P_{t-1}^{I}\right)+P_{t}^{I} I_{t}-P_{t}^{I} D I S P_{t}
$$

where:

$K_{t}=$ end-of-period real capital stock

$P_{t}^{I}=$ price of investment goods

$I_{t}=$ real gross investment

$D I S P_{t}=$ real revenues from sales of investment goods

$\delta=$ depreciation rate

We have assumed that capital depreciates at an annual rate of 8 percent and that the benchmark capital stock is on average three years old. The two-digit price indices of investment goods are from ISTAT.

\footnotetext{
${ }^{12}$ See, among others, Nucci and Pozzolo (2001) and Guiso and Parigi (1999). See Barca and others (1996) for a more detailed description of the methodology and the main features of the SIM.
} 


\section{Cash Flow}

Current cash flow, equal to net profits plus depreciation, is obtained from Centrale dei Bilanci.

\section{E. Disposals}

Revenues from sales of investment goods are from Centrale dei Bilanci.

\section{F. Investment}

Gross Total Investment in fixed assets is from the Survey of Investment in Manufacturing. Sampled firms are asked to report - for the year to which the survey refers - the total of "fixed investments in Italy" and their breakdown in "residential", "plant and machinery", and "transportation" investments. For data quality control, firms are also asked to report data - under the same headlines as above - referring to the previous year.

\section{G. Output}

Sales deflated by two-digit producer price indices have been used as proxy for real output. 
Table A1. Comparison of SIM and SIM-CADS Samples

\begin{tabular}{|c|c|c|c|c|}
\hline & \multicolumn{2}{|c|}{ SIM-CADS } & \multicolumn{2}{|c|}{ SIM } \\
\hline & Abs. Freq. & Rel. Freq. & Abs. Freq. & Rel. Freq. \\
\hline \multicolumn{5}{|l|}{ Sector } \\
\hline Private & 4,192 & 100 & 13,988 & 94.05 \\
\hline State-owned & 0 & 0 & 885 & 5.95 \\
\hline \multicolumn{5}{|l|}{ Location } \\
\hline North & 3,175 & 75.74 & 10,405 & 69.96 \\
\hline Center & 695 & 16.58 & 2,563 & 17.23 \\
\hline South & 322 & 7.68 & 1,905 & 12.81 \\
\hline \multicolumn{5}{|l|}{ Industrial Sector } \\
\hline Metallurgy & 438 & 10.45 & 1,664 & 11.19 \\
\hline Nonmetallic mineral products & 396 & 9.45 & 1,176 & 7.91 \\
\hline Chemical products & 409 & 9.76 & 1,274 & 8.57 \\
\hline Machinery & 598 & 14.27 & 2,254 & 15.15 \\
\hline Electrical goods & 259 & 6.18 & 1,313 & 8.83 \\
\hline Trains, ships, planes, and motor vehicles & 210 & 5.01 & 1,002 & 6.74 \\
\hline Food products, beverage, and tobacco & 359 & 8.56 & 1,416 & 9.52 \\
\hline Clothing and textiles & 739 & 17.63 & 2,238 & 15.05 \\
\hline Leather and footwear & 163 & 3.89 & 599 & 4.03 \\
\hline Timber and furniture & 69 & 1.65 & 234 & 1.57 \\
\hline Paper, printing, and publishing & 230 & 5.49 & 680 & 4.57 \\
\hline Rubber and plastic goods & 167 & 3.98 & 602 & 4.05 \\
\hline Other manufacturing goods & 155 & 3.70 & 421 & 2.83 \\
\hline \multicolumn{5}{|l|}{ Size } \\
\hline 50-99 employees & 579 & 13.81 & 2,925 & 19.67 \\
\hline 100-199 employees & 994 & 23.71 & 3,246 & 21.82 \\
\hline 200-499 employees & 1,247 & 29.75 & 4,203 & 28.26 \\
\hline 500-999 employees & 669 & 15.96 & 2,219 & 14.92 \\
\hline 1,000 and more employees & 703 & 16.77 & 2,280 & 15.33 \\
\hline Firm size (employees median) & \multicolumn{2}{|c|}{285} & \multicolumn{2}{|c|}{266} \\
\hline \begin{tabular}{|l|l|l|l|l|l|}
\multicolumn{9}{|c|}{} \\
Listed firms $(*)$ & 85 & 506 & 181 & 389 \\
\end{tabular} & 85 & 5.06 & 181 & 3.89 \\
\hline Firms belonging to a holding $(* *)$ & 668 & 67.34 & 1,922 & 62.95 \\
\hline Total observations & & & 14 , & \\
\hline
\end{tabular}

Notes: $(*)=$ reference year: $1997 ;(* *)=$ reference years: from 1996 to 1998 . 
Table A2. Balance of Panel

\begin{tabular}{cccccccccccc}
\hline & End: & 1990 & 1991 & 1992 & 1993 & 1994 & 1995 & 1996 & 1997 & 1998 & Firms \\
\hline Start & & & & & & & & & & \\
1987 & 16 & 18 & 20 & 20 & 18 & 14 & 7 & 16 & 85 & 214 \\
1988 & - & 8 & 4 & 6 & 2 & 1 & 1 & 2 & 16 & 40 \\
1989 & - & - & 1 & 3 & 1 & 4 & 1 & 1 & 8 & 19 \\
1990 & 1 & - & - & 17 & 18 & 8 & 7 & 12 & 73 & 136 \\
1991 & - & - & - & - & 3 & 2 & 6 & 7 & 16 & 34 \\
1992 & - & - & - & - & - & 4 & 3 & 6 & 13 & 26 \\
1993 & - & - & - & - & - & - & 13 & 5 & 31 & 49 \\
1994 & - & - & - & - & - & - & - & 7 & 20 & 27 \\
1995 & - & - & - & - & - & - & - & - & 19 & 19 \\
1996 & - & - & - & - & - & - & - & - & - & - \\
1997 & - & - & - & - & - & - & - & - & - & - \\
1998 & - & - & - & - & - & - & - & - & - & - \\
Firms & 17 & 26 & 25 & 46 & 42 & 33 & 38 & 56 & 281 & 564 \\
\hline
\end{tabular}

Table A3. Further Descriptive Statistics

\begin{tabular}{lccc}
\hline Variable & Median & Mean & Std. Dev. \\
\hline & & & \\
Real sales growth $\left(\Delta y_{t}\right)$ & 0.0253 & 0.0204 & 0.1377 \\
Employment & 285 & 877 & 4091 \\
Observations per firm & 9 & 8.5 & 2.7 \\
\hline
\end{tabular}




\section{REFERENCES}

Abel, Andrew B., 1983, “Optimal Investment under Uncertainty," American Economic Review, Vol. 73, 228-233.

Abel, Andrew B., and Janine C. Eberly, 1996, “Optimal Investment with Costly Reversibility," Review of Economic Studies, Vol. 63, 581-593.

- 1999, "The Effects of Irreversibility and Uncertainty on Capital Accumulation," Journal of Monetary Economics, Vol. 44, 339-377.

Arellano, Manuel, and Stephen Bond, 1991, "Some Tests of Specification for Panel Data: Monte Carlo Evidence and an Application to Employment Equations," Review of Economic Studies, Vol. 58, 277-297.

Arrow, Kenneth J., 1968, “Optimal Capital Policy with Irreversible Investment," in J. N. Wolfe (ed.), Value, Capital, and Growth, Papers in Honour of Sir John Hicks, Aldine Publishing Company, Chicago.

Attanasio, Orazio, Isabel dos Reis, and Lia Pacelli, 2000, “Aggregate Implications of Plant Level Investment Behaviour: Evidence from the UK ARD," mimeo, Institute for Fiscal Studies.

Barca, Fabrizio, and others, 1996, "Metodi e Risultati dell'Indagine sugli Investimenti delle Imprese Industriali,” Supplementi al Bollettino Statistico, Banca d'Italia, Vol. 59.

Bernanke, Ben S., Mark Gertler, and Simon Gilchrist, 1996, “The Financial Accelerator and the Flight to Quality," The Review of Economics and Statistics, Vol. 78, 1-15.

— 1998, “The Financial Accelerator in a Quantitative Business Cycle Framework," NBER Working Paper no. 6455.

Bertola, Giuseppe, 1988, “Irreversible Investment," Ph.D. Thesis, Massachusetts Institute of Technology, re-printed in Research in Economics 1998, Vol. 52, 3-37.

Bettoni, Andrea, 2000, “Capital Market Imperfections and Investment: Evidence from Firm Level Panel Data,” D.Phil. Thesis, University of Oxford.

Bigsten, Arne, and others, 1999, “Adjustment Costs, Irreversibility and Investment Patterns in African Manufacturing,” International Monetary Fund Working Paper no. 99/99.

Bloom, Nicholas, 2000, “The Real Options Effect of Uncertainty on Investment and Labour Demand," Institute for Fiscal Studies Working Paper no. 00/15. 
— Stephen R. Bond, and John Van Reenen, 2003, "Uncertainty and Company Investment Dynamics: Empirical Evidence for UK Firms," Centre for Economic Policy Research Discussion Paper no. 4025.

Blundell, Richard, and Stephen R. Bond, 1998, "Initial Conditions and Moment Restrictions in Dynamic Panel Data Models," Journal of Econometrics, Vol. 87, 115-143.

Bond, Stephen R., Julie A. Elston, Jacques Mairesse, and Benoit Mulkay, 2003, "Financial Factors and Company Investment in Belgium, France, Germany and the UK," Review of Economics and Statistics, Vol. 85, 153-165.

Bond, Stephen R., Dietmar Harhoff, and John Van Reenen, 1999, "Investment, R\&D and Financing Constraints in Britain and Germany," Institute for Fiscal Studies Working Paper no. 99/5.

Bond, Stephen R., and John Van Reenen, 2003, "Microeconometric Models of Investment and Employment," mimeo, Institute for Fiscal Studies, London, available at http://www.ifs.org.uk/innovation/bondvanrpdf.

Caballero, Ricardo, 1991, "On the Sign of the Investment Uncertainty Relationship," American Economic Review, Vol. 81, 279-288.

— , 1999, "Aggregate Investment," in John B. Taylor and Michael Woodford (eds.), Handbook of Macroeconomics, Vol. 1, North-Holland, Amsterdam.

Caballero, Ricardo, Eduardo M. R. A. Engel, and John C. Haltiwanger, 1995, "Plant-Level Adjustment and Aggregate Investment Dynamics," Brookings Papers on Economic Activity, Vol. 95, 1-54.

Carpenter, Robert E., and Laura Rondi, 2000, "Italian Corporate Governance, Investment, and Finance,” CERIS-CNR Working Paper no. 14/2000.

Carruth, Alan, Andrew Dickerson, and Andrew Henley, 2000, "What Do We Know About Investment Under Uncertainty,” Journal of Economic Surveys, Vol. 2, 119-153.

Dixit, Avinash (1997), "Investment and Employment Dynamics in the Short Run and the Long Run”, Oxford Economic Papers, Vol. 49, 1-20.

Dixit, Avinash, and Robert Pindyck, 1994, Investment Under Uncertainty, Princeton University Press, Princeton, New Jersey.

Doms, Mark, and Timothy Dunne, 1998, "Capital Adjustment Patterns in Manufacturing Plants,” Review of Economic Dynamics, Vol. 1, 409-429. 
Gelos, R. Gaston, and Alberto Isgut, 1999, "Fixed Capital Adjustment: Is Latin America Different? Evidence from the Colombian and Mexican Manufacturing Sectors," International Monetary Fund Working Paper no. 99/59.

Guiso, Luigi, and Giuseppe Parigi, 1999, "Investment and Demand Uncertainty," Quarterly Journal of Economics, Vol. 114, 185-227.

Hartman, Robert, 1972, “The Effects of Price and Cost Uncertainty on Investment," Journal of Economic Theory, Vol. 5, 258-266.

Hubbard, Glenn, 1998, “Capital-Market Imperfections and Investment," Journal of Economic Literature, Vol. 36, 193-225.

Lucas, Robert E. Jr., and Edward C. Prescott, 1971, “Investment Under Uncertainty," Econometrica, Vol. 39, 659-681.

Mairesse, Jacques, Hall H. Bronwyn, and Benoit Mulkay, 1999, "Firm-Level Investment in France and the United States: an Exploration of What We Have Learned in Twenty Years," NBER Working Paper no. 7437.

Nickell, Stephen J., 1977a, “The Influence of Uncertainty on Investment," Economic Journal, Vol. 86, 47-70.

- 1977b, "Uncertainty and Lags in the Investment Decision of Firms," Review of Economic Studies, Vol. 48, 249-263.

Nilsen, Anti O., and Fabio Schiantarelli, 2000, “Zeroes and Lumps in Investment: Empirical Evidence on Irreversibilities and Non-Convexities," Economics Department Working Paper no. 337, Boston College.

Nucci, Francesco, and Alberto F. Pozzolo, 2001, "Investment and the Exchange Rate: an Analysis with Firm Level Data,” European Economic Review, Vol. 45, 259-283.

Pattillo, Catherine A., 1998, “Investment, Uncertainty, and Irreversibility in Ghana," IMF Staff Papers, Vol. 45, 522-553.

Pindyck, Robert, 1988, "Irreversible Investment, Capacity Choice, and the Valuation of the Firm," American Economic Review, Vol. 78, 969-985.

Windmeijer, Frank, 2000, “A Finite Sample Correction for the Variance of Linear Two-Step GMM Estimators,” Institute for Fiscal Studies Working Paper no. 00/19. 